\title{
Foraging strategy of little auks under divergent conditions on feeding grounds
}

\author{
Katarzyna Wojczulanis-Jakubas, ${ }^{1}$ Dariusz Jakubas, ${ }^{1}$ Nina J. Karnovsky ${ }^{2} \&$ Wojciech Walkusz ${ }^{3}$ \\ 1 Department of Vertebrate Ecology and Zoology, University of Gdańsk, al. Legionów 9, PL-90-441 Gdańsk, Poland \\ 2 Department of Biology, Pomona College, 175 West Sixth Street, Claremont, CA 91711, USA \\ 3 Institute of Oceanology, Polish Academy of Sciences, ul. Powstańców Warszawy 55, PL-81-712 Sopot, Poland
}

Keywords

Alle alle; dual foraging strategy; foraging trip duration; little auk; Spitsbergen.

\section{Correspondence}

Katarzyna Wojczulanis-Jakubas, Department of Vertebrate Ecology and Zoology, University of Gdańsk, al. Legionów 9, PL-90-441 Gdańsk, Poland. E-mail: biokwj@univ.gda.pl

doi:10.1111/j.1751-8369.2009.00145.x

\begin{abstract}
A dual foraging strategy (long versus short trips) has been described for some species of seabirds, such as petrels, albatrosses (Procellariiformes) and penguins (Sphenisciphormes). Such a strategy has recently been reported for little auks (Alle alle) from the central coast of west Spitsbergen, Svalbard. This has been explained as a response to poor trophic conditions close to the breeding colony, and better conditions further away $(150 \mathrm{~km})$. In the present study, we investigated the foraging strategy of little auks in Hornsund, southern Spitsbergen, during two seasons with contrasting oceanographic conditions. During 2004, foraging conditions for little auks were good: cold Arctic waters rich in profitable high-energy food were dominant in their feeding grounds. Conversely, during 2006 there was a great influx of warm Atlantic water in the feeding area, inducing poor foraging conditions. In both seasons we examined the pattern of foraging trip lengths automatically with a video camera (both adults from four nests in each year), and by direct non-stop observation of 20-54 individually marked birds. Our results showed that the dual strategy and the ratio of short and long trips were consistent, regardless of the conditions in the feeding grounds. This suggests that the strategy is inherent and may be crucial for the self-maintenance of adults.
\end{abstract}

Making decisions about the allocation of energy, time and risks is an important task for each animal during reproduction. In long-lived animals, such as seabirds, excessive reproductive effort in a given breeding attempt may decrease their fitness, or even survival (Croxall \& Rothery 1991). Therefore, parents are often in conflict over how much care to provide to their offspring (Trivers 1974; Clutton-Brock 1991). Life-history theory predicts that parental investment in the case of long-lived animals should be adjusted to future reproductive prospects (Stearns 1992). Pelagic seabird parents depend on food resources far out at sea. Dispersion of the resources and constraints on transporting meals from feeding grounds to breeding areas have been suggested to be crucial in the development of the life-history strategies of seabirds (e.g., Weimerskirch 2007).

The chick-rearing period is the most demanding part of the breeding season, as adults have to forage not only for themselves but also for their offspring. Several Procellariiformes balance the needs of adults and offspring by the adoption of a two-fold provisioning strategy, whereby they alter the length of foraging trips during the chickrearing period, by making a series of short trips and then a single long trip. Short trips are believed to be for chick provisioning, whereas during the longer trips adults forage mainly for their own food, and only secondarily collect food for offspring (Weimerskirch et al. 1994; Grandeiro et al. 1998). While carrying out this strategy, blue petrel (Halobaena caerulea) adults systematically gain mass during the long trips, and lose this stored energy during the following short trips (Chaurand $\&$ Weimerskirch 1994). Some studies suggest that foraging trip duration may vary with foraging location. During short trips, birds forage closer to the breeding ground in comparison with longer trips (e.g., Catard et al. 2000). This way, birds may increase the frequency of chick feeding, which in turn favours food assimilation by chicks, and their growth rates and subsequent survival (Schaffner 1990). During their long trips parents have more time to acquire food, and may exploit remote but richer food 
areas, and can thereby more effectively restore body reserves (Weimerskirch et al. 1997).

The little auk (Alle alle) is a small planktivorous Atlantic alcid nesting in colonies in rock debris or crevices on mountain slopes. It is considered to be the most numerous seabird in the High Arctic (Stempniewicz 2001). It is believed to have the highest metabolic rate among all seabirds. An adult bird consumes on average $696 \mathrm{~kJ}$ per day (Gabrielsen et al. 1991; Konarzewski et al. 1993). Little auks forage almost exclusively on planktonic crustaceans, and focus on zooplankters associated with cold Arctic waters, which are larger and much richer in energy than those originating from Atlantic waters (Karnovsky et al. 2003; Jakubas et al. 2007). Like many seabirds, a little auk pair raises only one chick per season. Energetic demands of the semi-precocial chick, however, are relatively high (on average $262 \mathrm{~kJ}$ per day; Konarzewski et al. 1993), and in order to meet its requirements each parent performs 50-80 food trips (WojczulanisJakubas 2007) during roughly 27 days of chick rearing (Stempniewicz 2001).

Steen et al. (2007) studied the foraging strategy of little auks in central Spitsbergen, Svalbard, and found a dual pattern of trips. They suggested that the pattern might be a response to the low availability of nutrient-rich food close to the studied colony. The purpose of our study was to determine whether this strategy of making dual trips is a response to actual feeding conditions or, alternatively, a fixed strategy guided by the necessity of adult self-feeding. We examined the little auk foraging trip pattern and duration at a big colony in Hornsund, in southern Spitsbergen, during two years with contrasting oceanographic conditions. We hypothesized that if dual food trips are a response to the poor quality of foraging areas near their colony, then this pattern should not be present when conditions are more favourable. Alternatively, if it is a fixed strategy then it should be evident in both situations.

\section{Material and methods}

The fieldwork was conducted in the little auk breeding colony situated on the Ariekammen slope $\left(77^{\circ} 00^{\prime} \mathrm{N}\right.$, $\left.15^{\circ} 33^{\prime} \mathrm{E}\right), 1.5 \mathrm{~km}$ north off the Hornsund fjord coast, south-west Spitsbergen, from 20 July to 10 August (the whole chick-rearing period) in 2004, and from 20 June to 2 August (incubation and the first 3 weeks of the chickrearing period) in 2006. These two years differed dramatically in terms of oceanographic conditions. The 2004 year was classified as a "cold" one because of the significant presence of the cold Arctic water masses in the Hornsund area. In 2006 the water masses there were significantly warmer, and the year was classified as a "warm" one. This classification was based on hydrological measurements (Walczowski \& Piechura 2006; Walkusz 2006) as well as the presence of ice-pack in June and July 2004; there was no ice during the same months in 2006 in the Hornsund fjord area, as shown on satellite ice-pack range images available from the website of the Institute of Environmental Physics, University of Bremen (http:// 157.249.32.242/archive/). The occurrence of ice-pack in the area is associated with the inflow of Arctic waters carried by the cold Sørkapp Current (Węsławski \& Kwaśniewski 1990). The distribution of water masses in 2004 in this area was further confirmed by sea-surface temperature and salinity measurements along the west Spitsbergen coast (Berge et al. 2005).

\section{Fieldwork}

Foraging trip duration was calculated based on the presence of individually marked birds at the nest territory. It was recorded automatically by video cameras and directly by two observers. Birds were caught in nests during incubation and marked with distinct colour marks on breast feathers and a combination of colour rings. Additionally, for better identification, the entrances to the nests of marked birds, situated in chambers among rock debris, were labelled.

Two video recorders connected to two video cameras (HS - 166 Color CCD Camera; Mintron, Taipei, Taiwan) monitored the entrance of four nests with both parents marked during both seasons. Three of the four nests with the same birds were recorded during both seasons. Data were collected continuously $24 \mathrm{~h}$ a day for 23-27 consecutive days of the chick-rearing period (1-27-day-old chicks) in 2004, and for 14 consecutive days (1-15-day-old chicks) in 2006. The time between the disappearance of the marked bird from the field of camera view (usually after leaving the nest) and appearing there again was regarded as a foraging trip. Birds were identified when entering (usually with full gular pouch) and/or exiting the nest. All marked birds were positively identified in the recorded material.

During nine 24-h non-stop direct watches, individually marked birds (20-39 in 2004 and 52-54 in 2006) were observed continuously. Four watches were performed during the chick-rearing period in 2004 (I, when the median age of the chicks in observed nests was 5 days old; II when the median age was 11 days old; III, when the median age was 19 days old; IV, when the median age was 24 days old) and five in 2006 (I, 2 days old; II, 5 days old; III, 8 days old; IV, 13 days old; V, 22 days old). The time between the last observation of the marked bird and its next appearance in the colony area with a full gular pouch was regarded as a foraging trip. Bird identity was established without any problem throughout the whole period of observation. 
Additionally, four 24-h continuous watches were performed during incubation in 2006 (days of incubation according to the median: I, 9th day; II, 15th day; III, 19th day; IV, 27th day). Foraging trips of birds were then recorded in the same way as described above for the chick-rearing period. During the whole incubation, the median of duration of trips performed by observed birds was $530 \mathrm{~min}\left(Q_{1}-Q_{3}=310-690 \mathrm{~min} ; N=87\right)$. This duration did not change significantly in the course of the incubation period (Kruskal-Wallis test, $H_{3}=5.09, N=87$, $P=0.17)$. We assumed that foraging trips lasting $530 \mathrm{~min}$ (the median duration of foraging trips in the incubation period) or longer serve as self-provisioning trips of adult little auks. Based on that assumption, we divided the foraging trips observed during the chick-rearing period into two groups: (1) long trips (LTs; representing the needs of adults), lasting as long as the median or longer; and (2) short trips (STs; for chick provisioning only), lasting less than the median for incubation. When divided this way, STs constituted 72 and $71 \%$ of all trips in 2004 and 2006, respectively.

To examine the little auks' diet, we caught 48 and 46 adult birds with full gular pouches in the colony with mist-nets in 2004 (when the chicks were 8-24 days old, according to the hatching median) and in 2006 (when the chicks were 7-20 days old), respectively. The food was gently scooped out from the pouch with a small plastic spoon. The loads were preserved in $40 \%$ alcohol until further analyses at the Institute of Oceanology, Polish Academy of Sciences. Birds were released without any harm after approximately $5 \mathrm{~min}$ of handling.

Phenological parameters such as egg-laying and hatching timing were determined by the day-to-day examination of a group of 33 nests in 2004, and 67-81 nests in 2006 (partial overlap of marked and phenologically controlled pairs, but both groups bred in the same patch of the colony). The age of chicks and/or stage of the incubation and chick rearing were estimated according to the median of egg-laying and/or hatching.

\section{Laboratory analyses}

Prior to prey item identification, food samples were rinsed with fresh water. Prey items larger than $1 \mathrm{~cm}$ in length were picked out and identified before the rest of the sample was divided into subsamples using a micropipette. Food items were identified to the lowest possible taxonomical level. Copepods were identified to developmental stages. To distinguish the three Calanus species, the identification criteria given by Kwaśniewski et al. (2003) were applied. Dry weight and energy values of food loads delivered to chicks by males and females were calculated according to data in the literature (Kosobokova 1980;
Percy \& Fife 1981; Wołowicz \& Szaniawska 1986; Berestovskii et al. 1989; Węsławski \& Kwaśniewski 1990; Mumm 1991; Richter 1994; Węsławski et al. 1994; Hansen 1997; Poltermann 1997; Węsławski, Stempniewicz et al. 1999; Węsławski, Koszteyn et al. 1999; Karnovsky et al. 2003).

The following species noted in our study are regarded as Arctic water representatives: Apherusa glacialis, Calanus glacialis, C. hyperboreus, Gammarus wilkitzkii, Onisimus glacialis, Themisto libellula (Węsławski \& Kwaśniewski 1990; Hirche 1991; Unstad \& Tande 1991). Moreover, A. glacialis, G. wilkitzkii and O. glacialis are considered to be sympagic (ice-associated) species (Gulliksen \& Lønne 1991).

Interannual differences in foraging trip duration were tested with the non-parametrical tests (Mann-Whitney $U$-test). Percentage data on contribution of zooplankton items associated with cold waters in food loads were normalized by arcsin-square root transformation before making interannual comparisons. Descriptive statistics are expressed as means \pm SDs or median and $25 \%\left(Q_{1}\right)$ and $75 \%\left(Q_{3}\right)$ quartiles.

\section{Results}

\section{Foraging trip duration}

Analyses of video recordings showed that foraging trip duration did not change significantly across four consecutive weeks of chick rearing during the cold year of 2004 (Kruskal-Wallis test, $H_{3}=1.33, N=322, P=0.72$ ). Direct observations showed that the duration of foraging trips (mainly consisting of STs: 85\%, N= 59 in 2004; 87\%, $N=318$ in 2006) was generally similar in the course of the chick-rearing period in both seasons. But adults made significantly shorter trips when their chicks were 2-6 days old compared with when they were 22-26 days old (2004, Kruskal-Wallis test, $H_{3}=10.70, N=125, P=0.01$, Dunn's test, $P<0.05 ; 2006$, Kruskal-Wallis test, $H_{4}=15.10, N=540, P=0.005$, Dunn's test, $P<0.05$; Fig. 1).

We found no interannual differences in foraging trip duration recorded on video during the first ( $U$-test, $Z=-1.47, \quad N=161, \quad P=0.14)$ and second ( $U$-test, $Z=1.50, N=208, P=0.13)$ weeks of the chick-rearing period. The interannual comparison of direct observations showed that food trip duration did not reveal any significant differences between phenologically equivalent watches ( $U$-tests: I versus II watch, $Z=1.47, N=133$, $P=0.14$; II versus IV watch, $Z=0.51, N=204, P=0.61$; IV versus V watch, $Z=1.00, N=67, P=0.32$ ).

In both years we found a pattern of alternating STs and LTs (see Fig. 2). The majority of LTs were both preceded and followed by at least one ST. Interannual differences in 
Fig. 1 The duration of foraging trips of the little auks (Alle alle) recorded in consecutive watches performed throughout the chickrearing period in the "cold" season of 2004 and in the "warm" season of 2006. Significant differences between particular watches are marked with the arrows (Kruskal-Wallis and Dunn's tests, $P<0.05$; see text for details).
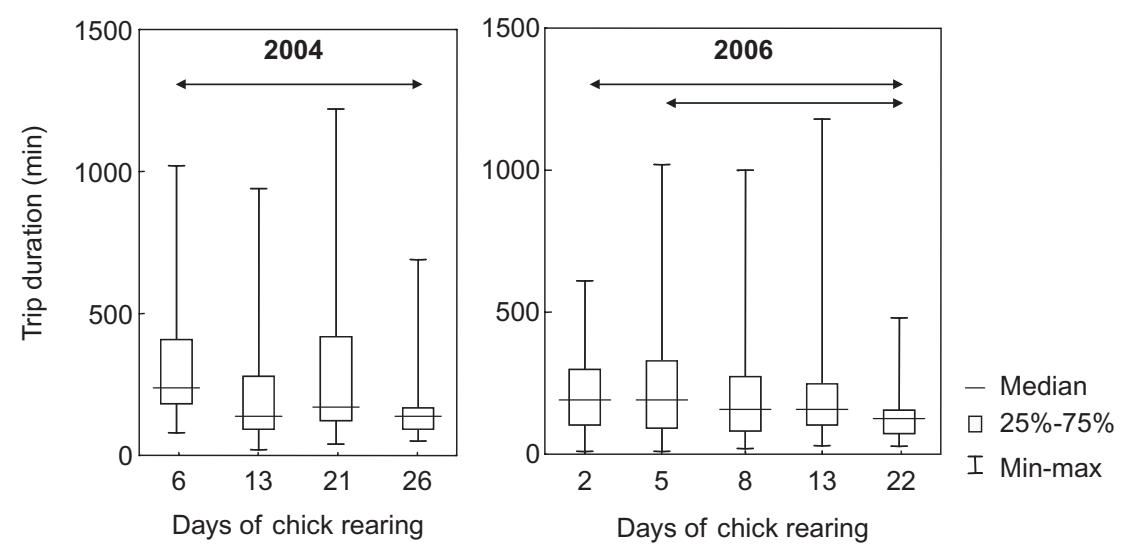
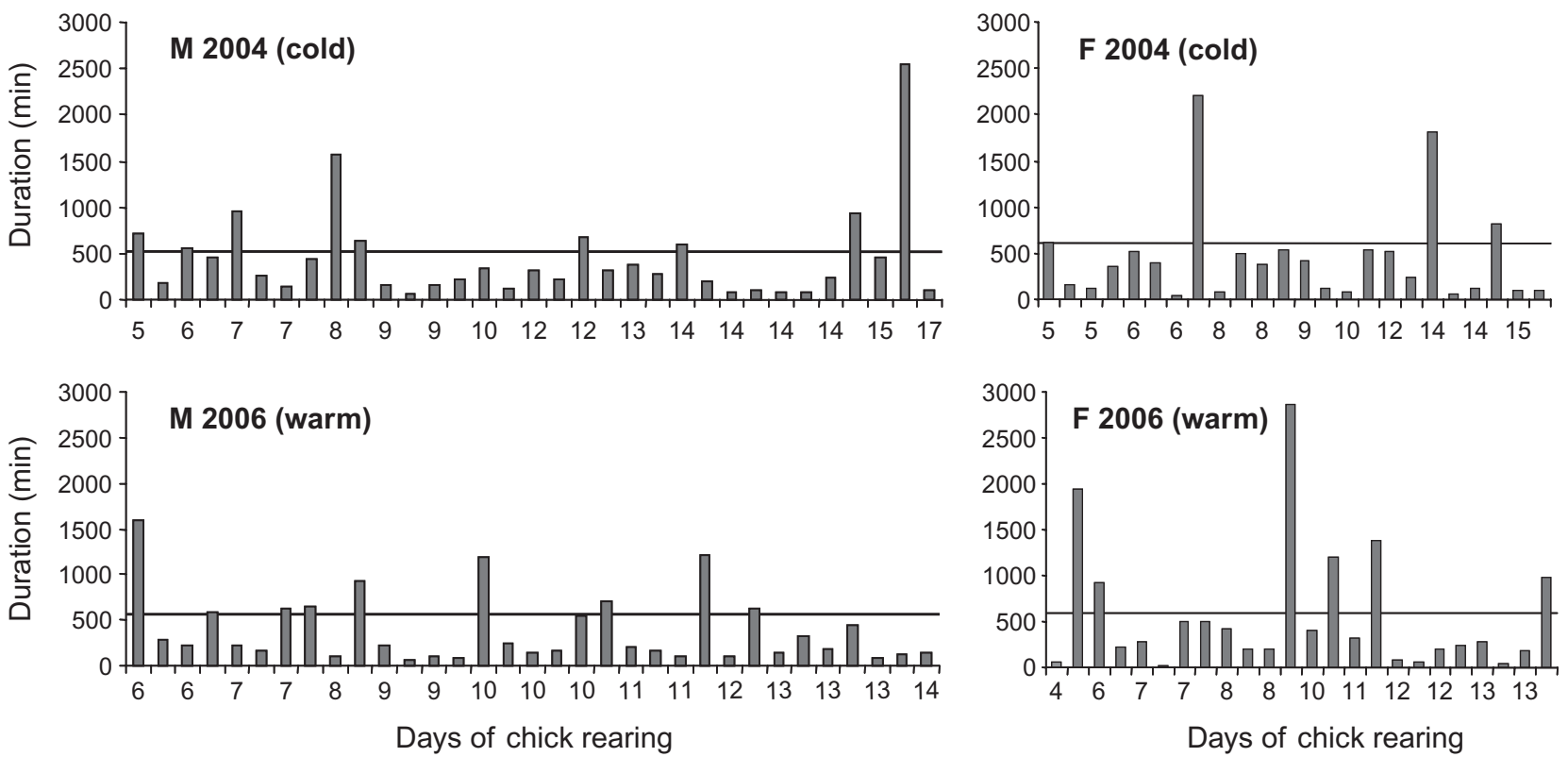

Fig. 2 The duration of the trips of one individual male and one individual female little auk (Alle alle), a breeding pair, during the second week of chick rearing in two seasons with different foraging conditions in the feeding grounds. The horizontal line indicates the assumed division between short and long trips.

the proportion of these cases were not found $\left(\chi^{2}\right.$ tests in Table 1). The duration of LTs was not correlated with the number of STs preceded or followed by STs in any season (Pearson correlation coefficients, $P>0.05$ ).

The duration of STs and LTs recorded on video did not differ between the two years (Table 2). The proportion of LTs and STs was similar in both seasons $(1: 2.6$ in cold 2004 and $1: 2.5$ in warm 2006; $\chi^{2}{ }_{1}=0.02, P=0.90$ ).

Regardless of the season, the frequency of foraging trips in particular duration classes was similar in both seasons (Kolmogorow-Smirnow test, $D<0.01, N=20, P>0.10$; Fig. 3). Among the STs, the most common was $2-3 \mathrm{~h}$ (Fig. 3).

\section{Chick diet}

In both years birds delivered a similar number of zooplankton items per food load (on average $1320 \pm 491.8$, $N=48$, in 2004, and $1337 \pm 516.6, N=46$, in 2006; Student's $t$-test, $t_{92}=0.15, P=0.88$ ). The interannual comparison of caloric value of food load did not reveal any significant differences (on average $25.2 \pm 8.2 \mathrm{~kJ}$ per food load, $N=48$, in 2004, and $23.7 \pm 8.9, N=46$, in 2006; Student's $t$-test, $t_{92}=-0.86, P=0.39$ ).

Regardless of the year, Calanus glacialis CV, associated with cold water masses, was the most abundant zooplankton item, both in terms of number and frequency of 
Table 1 Proportion of the cases when a long trip (LT) performed by the little auks (Allealle) was preceded and followed by at least one short trip (ST) in the "cold" season of 2004 and in the "warm" season of 2006, in Hornsund, southern Spitsbergen, Svalbard, with results of $\chi^{2}$ tests for an examination of the interannual comparison.

\begin{tabular}{llll}
\hline Season & \% of cases with & Followed LT & Preceeded LT \\
\hline 2004 (cold) & at least one ST & $70 \%(N=88)$ & $71 \%(N=95)$ \\
2006 (warm) & at least one ST & $72 \%(N=81)$ & $71 \%(N=80)$ \\
Interannual comparison $\left(\chi^{2}\right.$ test) & $\chi^{2}$ & 0.24 & 0.58 \\
& $P$ & 0.63 & 0.45 \\
\hline
\end{tabular}

Table 2 Duration of short (STs) and long trips (LTS) performed by the little auks (Alle alle) in the "cold" season of 2004 and in the "warm" season of 2006, in Hornsund, southern Spitsbergen, Svalbard, with results of $U$-tests for interannual comparison.

\begin{tabular}{llllll}
\hline $\begin{array}{l}\text { Foraging } \\
\text { trip } \\
\text { category }\end{array}$ & $\begin{array}{l}\text { Season 2004 (cold) } \\
\text { Median }\left(Q_{1}-Q_{3} ; N\right)\end{array}$ & $\begin{array}{l}\text { Season 2006 (warm) } \\
\text { Median }\left(Q_{1}-Q_{3} ; N\right)\end{array}$ & & & \\
{$[$ min $]$} & & $Z$ & $N$ & $P$ \\
\hline STs & $190(117-296 ; 114)$ & $195(105-339 ; 215)$ & 0.14 & 329 & 0.89 \\
LTs & $767(600-1267 ; 50)$ & $815(625-1059 ; 90)$ & 0.15 & 140 & 0.88 \\
\hline
\end{tabular}
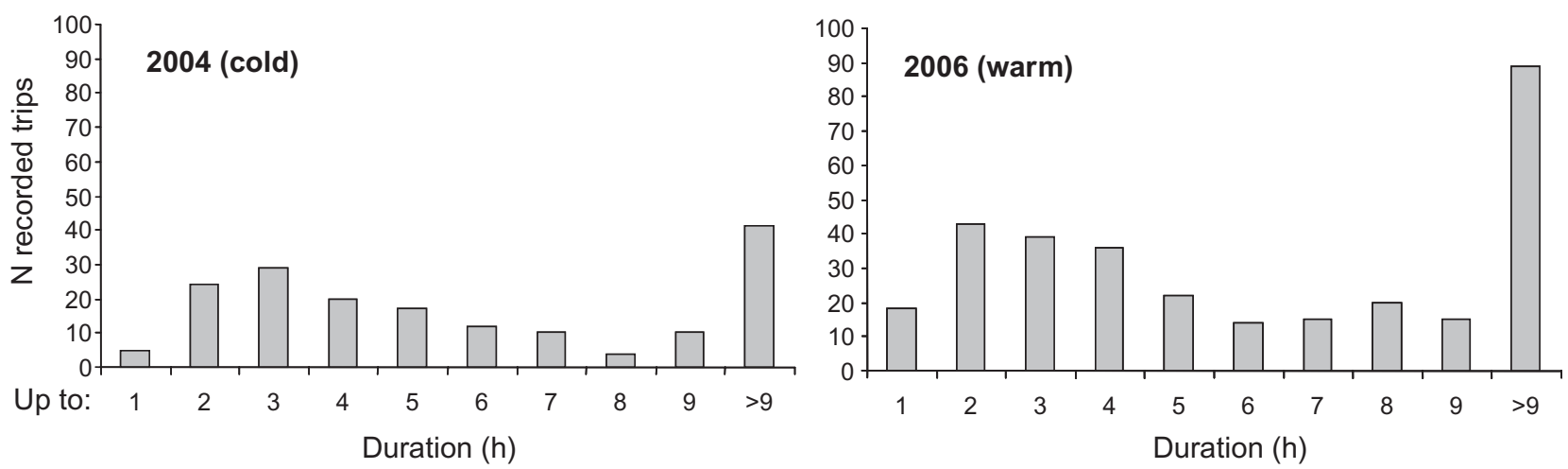

Fig. 3 The frequency of foraging trips of the little auk (Alle alle) in particular ranges of trip duration during the first 2 weeks of the chick rearing period in the "cold" season of 2004 and in the "warm" season of 2006 (from video data).

occurrence (Table 3). The proportion of all zooplankton items associated with cold water masses in particular food loads was higher in the cold 2004 (mean: 88.1 $\pm 9.6 \%$, $N=48$ ) than in the warm 2006 (mean: $82.9 \pm 13.0 \%$, $N=46$; Student's $t$-test, $t_{92}=-2.33, P=0.02$, for transformed percentage data).

\section{Discussion}

We observed no differences in the foraging trip duration and pattern of little auks between the two seasons with contrasting environmental conditions (cold versus warm) in their feeding grounds. The finding of a dual foraging strategy is consistent with the study of Steen et al. (2007), which was carried out in Isfjorden, north of the studied area. The dual foraging strategy is evident despite the different ways data were collected (video cameras in the study reported here versus the passive integrated transponder [PIT] tags used by Steen et al.). Quite striking is the consistent ratio of STs to LTs in both years of this study $(2.5-2.6: 1)$ with the ratio described by Steen et al. $(2: 1)$. The similarity of the foraging patterns of little auks during the two seasons suggests a fixed strategy, possibly playing an important role in adult self-maintenance.

It is highly likely that during STs little auks forage mainly to provision chicks. Assuming that the feeding area of little auks is $20-80 \mathrm{~km}$ from the colony (Karnovsky et al. 2003), a flight speed of $60 \mathrm{~km} \mathrm{~h}^{-1}$ (Pedersen \& Falk, unpubl. data), and time for collecting enough food for one load for a chick (a foraging pace of 6.4 items per second [Harding et al. 2009] at on average ca. 1300 items per load [this study]), little auks need 40-160 min for the shortest foraging flights. 
Table 3 The average abundance (average percentage of number of items in the samples) and frequency of occurrence of different zooplankton items in food loads collected from little auks (Alle alle) in the "cold" season of $2004(N=48)$ and in the "warm" season of 2006 ( $N=46)$, in Hornsund, southern spitsbergen, Svalbard.

\begin{tabular}{|c|c|c|c|c|}
\hline \multirow[b]{3}{*}{ Species } & \multicolumn{4}{|l|}{ Season } \\
\hline & \multicolumn{2}{|l|}{ Cold 2004} & \multicolumn{2}{|l|}{ Warm 2006} \\
\hline & $\begin{array}{l}\text { Abundance } \\
\%\end{array}$ & $\begin{array}{l}\text { Freq. of } \\
\text { occurence \% }\end{array}$ & $\begin{array}{l}\text { Abundance } \\
\%\end{array}$ & $\begin{array}{l}\text { Freq. of } \\
\text { occurence } \%\end{array}$ \\
\hline Calanus hyperboreus (AF, CV, CIV) & 0.5 & 65 & 0.2 & 35 \\
\hline Calanus glacialis (AM, AF, CIV, CIII) & 14.1 & 100 & 5.6 & 98 \\
\hline Calanus glacialis (CV) & 69.6 & 100 & 76.1 & 100 \\
\hline Calanus finmarchicus (AM, AF, CIV, CIII) & 1.3 & 90 & 1.8 & 78 \\
\hline Calanus finmarchicus (CV) & 4.2 & 98 & 9.2 & 100 \\
\hline Other copepods from Arctic waters & 0.001 & 100 & 0.03 & 100 \\
\hline Other copepods & 0.02 & 94 & 0.005 & 4 \\
\hline Decapods from Arctic waters & 0.1 & 90 & 0.4 & 93 \\
\hline Other decapods & 4.7 & 85 & 4.6 & 83 \\
\hline Amphipods from Arctic waters & 3.8 & 90 & 0.4 & 98 \\
\hline Other amphipods & 0.2 & 98 & 0.3 & 70 \\
\hline Euphasiids & 1.4 & 98 & 1.2 & 98 \\
\hline Others zooplankton items & 0.1 & 85 & 0.04 & 100 \\
\hline
\end{tabular}

Having such high-energy demands and a long chickrearing period, adults have to replenish their own reserves systematically, and LTs may serve this purpose. Travelling great distances a few times per day may be energetically expensive for the small birds performing flapping flight. A compensation for an energy loss has to be considered. Although the body mass of little auks drops abruptly after hatching, it remains stable until the end of chick-rearing period, which suggests that adults are rebuilding basic reserves systematically during that period. Moreover, digestive tract mass of the adults increases by half through the breeding period (Taylor 1994), indicating a high rate of self-feeding.

It has been observed for several species of Procellariiformes that have a dual foraging strategy that during long foraging trips birds reach more remote areas than during short ones (Weimerskirch et al. 1997; Catard et al. 2000). It cannot be excluded that this is also the case for little auks. Steen et al. (2007) hypothesized that little auks in Isfjorden utilize different areas during STs and LTs. This was based on the different composition of chick meals. However, in our opinion, the composition of chick meals alone does not conclusively indicate feeding ground locations. In our view, it is not possible to determine the location of feeding grounds visited during STs or LTs without using such methods as attaching tracking equipment to birds.

During LTs, little auks might not only forage but may also rest. Resting at sea may be more efficient and safer than in the colony, where predators, mainly the glaucous gull (Larus hyperboreus), are virutally ever-present. Little auks spend one-fifth of their time outside the nest in the colony, circling over the colony after being scared off by glaucous gulls (Wojczulanis et al. 2005). Thaxter et al. (2009) reported that common guillemots (Uria aalge) spend $46 \%(2-5 \mathrm{~h})$ of their time at sea in the chickrearing period on the surface of the water, outside of foraging periods. Although that resting time requires more detailed investigation of its functionality, it is possible that the closely related little auk exhibits a similar pattern.

Some differences in the duration of little auk foraging trips in the course of the chick-rearing period may spring from the body condition of some parents and/or their parental duties. It has been reported for some Procellariiformes that foraging trip duration can be flexible. The body condition of adults seems to be the main factor determining variations in trip length (Weimerskirch 1998; Weimerskirch et al. 1999; Duriez et al. 2000). This may be also true for the little auk, but further studies are needed. The slightly shorter trips at the end of the chickrearing period may also be related somehow to the cessation of chick feeding at this time by females (Harding et al. 2004; Wojczulanis-Jakubas 2007).

To cover high-energy requirements, little auks focus on energy-rich food items associated with cold Arctic waters. Even in suboptimal conditions in feeding grounds (influx of warm water masses), the chick diet is made up mainly of the Arctic zooplankton items (e.g., Karnovsky et al. 2003; Jakubas et al. 2007). However, slight but significant interseasonal differences in chick diet were found in the present study. It is possible that searching for preferred food items in suboptimal conditions was less favourable, but did not significantly change the food trip pattern. This 
suggests that the strategy is not very flexible, and seems to be a fixed one, possibly allowing adult self-maintenance during the energetically demanding chick-rearing period.

\section{Acknowledgements}

We thank Monika Bożeńska and Anna Golba for their efforts in the video material analysis, and Allison Bailey for assistance in the field in 2006. Big thanks also go to the staff of the Polish Polar Station in Hornsund (Institute of Geophysics, Polish Academy of Sciences) for all of their kind assistance. We are also grateful to Prof. Lech Stempniewicz for his comments on an earlier version of the manuscript. The study was financially supported by grants from the University of Gdańsk (BW 1140-50162-3) and the Ministry of Education and Science $(0640 /$ PO4/2005/29) and grants to N.J. Karnovsky from the National Science Foundation, Arctic Natural Resources Division, and International Science and Engineering Division. All birds were handled with the permission of the Norwegian Animal Research Authority and the Governor of Svalbard.

\section{References}

Berestovskii E.G., Anisimova N.A., Denisenko C.G., Luppova E.N., Savinov V.M. \& Timofeev C.F. 1989. Relationships between size and body mass of some invertebrates and fish of the north-east Atlantic. Apatity: Murman Marine Biological Institute, USSR.

Berge J., Johnsen G., Nilsen F., Gulliksen B. \& Slagstad D. 2005. Ocean temperature oscillations enable reappearance of blue mussels Mytilus edulis in Svalbard after a 1000 year absence. Marine Ecology Progress Series 303, 167-175.

Catard A., Weimerskirch H. \& Cherel Y. 2000. Exploitation of distant Antarctic waters and close shelf-break waters by white-chinned petrels rearing chicks. Marine Ecology Progress Series 194, 249-261.

Chaurand T. \& Weimerskirch H. 1994. The regular alternation of short and long foraging trips in the blue petrel Halobaena caerulea: a previously undescribed strategy of food provisioning in a pelagic seabird. Journal of Animal Ecology 63, 275-282.

Clutton-Brock T.H. 1991. The evolution of parental care. Princeton: Princeton University Press.

Croxall J.P. \& Rothery P. 1991. Population regulation of seabirds: implications of their demography for conservation. In C.M. Perrins et al. (eds.): Bird population studies. Pp. 272-296. Oxford: Oxford University Press.

Duriez O., Weimerskirch H. \& Fritz H. 2000. Regulation of chick provisioning in the thin-billed prion: an interannual comparison and manipulation of parents. Canadian Journal of Zoology 78, 1275-1283.
Gabrielsen G.W., Taylor J.R.E., Konarzewski M. \& Mehlum F. 1991. Field and laboratory metabolism and thermoregulation in dovekies (Alle alle). Auk 108, 71-78.

Grandeiro J.P., Nunes M., Silva M.C. \& Furness R.W. 1998. Flexible foraging strategy of Cory's shearwater Calonectris diomedea, during chick rearing period. Animal Behaviour 56, 1169-1176.

Gulliksen B. \& Lønne O.J. 1991. Sea ice macrofauna in the Antarctic and Arctic. Journal of Marine Systems 2, 53-61.

Harding A.M.A., Egevang C., Walkusz W., Merkel F., Blanc S. \& Grémillet D. 2009. Estimating prey capture rates of a planktivorous seabird, the little auk (Alle alle), using diet, diving behaviour, and energy consumption. Polar Biology 32, 785-796.

Harding A.M.A., Pelt T.I.V., Lifjeld J.T. \& Mehlum F. 2004. Sex differences in little auk Alle alle parental care: transition from biparental to parental-only care. Ibis 146, 642-651.

Hansen H. 1997. Mesozooplankton of the Laptev Sea and the adjacent eastern Nansen Basin-distribution and community structure in late summer. Reports on Polar Research 229, 131.

Hirche H.J. 1991. Distribution of dominant calanoid copepod species in the Greenland Sea during late fall. Polar Biology 11, 351-362.

Jakubas D., Wojczulanis-Jakubas K. \& Walkusz W. 2007. Response of dovekie to changes in food availability. Waterbirds 30, 421-428.

Karnovsky N.J., Kwaśniewski S., Węsławski J.M., Walkusz W. \& Beszczyńska-Möller A. 2003. The foraging behaviour of little auks in a heterogenous environment. Marine Ecology Progress Series 253, 289-303.

Konarzewski M., Taylor J.R.E. \& Gabrielsen G.W. 1993. Chick energy requirements and adult energy expenditures of dovekies (Alle alle). Auk 110, 343-353.

Kosobokova K.N. 1980. Caloric value of some zooplankton representatives from the central Arctic Basin and the White Sea. Oceanology 20, 84-89.

Kwaśniewski S., Hop H., Falk-Petersen S. \& Pedersen G. 2003. Distribution of Calanus species in Kongsfjorden, a glacial fjord in Svalbard. Journal of Plankton Research 25, $1-20$.

Mumm N. 1991. On the summerly distribution of mesozooplankton in the Nansen Basin, Arctic Ocean. Reports on Polar Research 92. Bremerhaven: Alfred Wegener Institute for Polar and Marine Research.

Percy J.A. \& Fife F.J. 1981. The biochemical composition and energy content of Arctic marine macrozooplankton. Arctic 34, 307-313.

Poltermann M. 1997. Biology and ecology of cryopelagic amphipods from Arctic sea ice. Reports on Polar Research 225. Bremerhaven: Alfred Wegener Institute for Polar and Marine Research.

Richter C. 1994. Regional and seasonal variability in the vertical distribution of mesozooplankton in the Greenland Sea. Reports on Polar Research 154. Bremerhaven: Alfred Wegener Institute for Polar and Marine Research. 
Schaffner F.C. 1990. Food provisioning by white-tailed tropicbird: effect on the development pattern of the chick. Ecology 71, 375-390.

Stearns S.C. 1992. The evolution of life histories. Oxford: Oxford University Press.

Steen H., Vogedes D., Broms F., Falk-Petersen S. \& Berge J. 2007. Little auks (Alle alle) breeding in a High Arctic fjord system: bimodal foraging strategies as a response to poor food quality? Polar Research 26, 118-125.

Stempniewicz L. 2001. Little auk Alle alle. The Journal of the Birds of the Western Palearctic 3, 175-20.

Taylor J.R.E. 1994. Chances in body reserves of breeding little Auks (Alle alle L.). Polish Polar Research 123, 147-169.

Thaxter C.B., Daunt F., Hamer K.C., Watanuki Y., Harris M.P., Gremillet D. \& Wanless S. 2009. Sex-specific food provisioning in a monomorphic seabird, the common guillemot Uria aalge: nest defense, foraging efficiency, parental effort? Journal of Avian Biology 40, 75-84, doi:10.1111/j.1600-048X.2008.04507.x.

Trivers R. 1974. Parent-offspring conflict. American Zoologist 14, 249-264.

Unstad K.H. \& Tande K.S. 1991. Depth distribution of Calanus finmarchicus and C. glacialis in relation to environmental conditions in the Barents Sea. In: E. Sakshaug et al. (eds.): Proceedings of the Mare Symposium Polar Marine Ecology, Trondheim, 12-16 May 1990. Polar Research 10, 409-420.

Walczowski W. \& Piechura A. 2006. New evidence of warming propagating toward the Arctic Ocean. Geophysical Research Letters 33, doi:10.1029/2006GL025872.

Walkusz W. 2006. Temporal and spatial variability of zooplankton from two Svalbard fjords: Kongsfjorden and Hornsund. $\mathrm{PhD}$ thesis, Institute of Oceanology, Polish Academy of Science, Sopot.

Weimerskirch H. 1998. How can a pelagic seabird provision its chick when relying on a distant food resources? Cyclic attendance at the colony, foraging decision and body condition in sooty shearwaters. Journal of Animal Ecology 67, 99-109.

Weimerskirch H. 2007. Are seabirds foraging for unpredictable resources? Deep-Sea Research Part II 54, 211-223.
Weimerskirch H., Chastel O., Chaurand T., Ackerman L., Hindermeyer X. \& Judas J. 1994. Alternate long and short foraging trips in pelagic seabird parents. Animal Behaviour 47, 472-476.

Weimerskirch H., Cherel Y., Cuenot-Chaillet F. \& Ridoux V. 1997. Alternative foraging strategy and resources of allocation by male and female of wandering albatrosses. Ecology 78, 2051-2063.

Weimerskirch H., Fradet G. \& Cherel Y. 1999. Natural and experimental changes in chick provisioning in a long lived seabird, the Antarctic prion. Journal of Avian Biology 30, 165-174.

Węsławski J.M., Koszteyn J., Kwaśniewski S., Stempniewicz L. \& Malinga M. 1999. Summer food resources of the little auk, Alle alle (L.) in the European Arctic seas. Polish Polar Research 20, 387-403.

Węsławski J.M. \& Kwaśniewski S. 1990. The consequences of climatic fluctuations for the food web in Svalbard coastal waters. In M. Barnes \& R.N. Gibson (eds.): Trophic relationships in the marine environment. Proceedings of the 24th European Marine Biology Symposium. Pp. 281-295.

Aberdeen: Aberdeen University Press.

Węsławski J.M., Stempniewicz L. \& Galaktionov K. 1994. Summer diet of seabirds from the Franz Josef Land archipelago, Russian Arctic. Polar Research 13, 173-181.

Węsławski J.M., Stempniewicz L., Mehlum F. \& Kwaśniewski S. 1999. Summer feeding strategy of the little auk Alle alle from Bjornøya, Barents Sea. Polar Biology 21, 129-134.

Wojczulanis K., Jakubas D. \& Stempniewicz L. 2005. Changes in the glaucous gull predatory pressure on little auk in southwest Spitsbergen. Waterbirds 28, 430-435.

Wojczulanis-Jakubas K. 2007. Inwestycje rodzicielskie samca $i$ samicy u monogamicznego gatunku ptaka morskiego (alczyk Alle alle) $w$ warunkach dnia polarnego. (Male and female parental investments in monogamous seabird [the little auk Alle alle] in the circumstances of the midnight sun.) PhD thesis, University of Gdańsk.

Wołowicz M. \& Szaniawska A. 1986. Calorific value, lipid content and radioactivity of common species from Hornsund, southwest Spitsbergen. Polar Research 4, 79-84. 